\title{
Different doses of folic acid and vitamin B12 to treat rabbits with deep venous thrombosis and hyperhomocysteinemia
}

\author{
XIAO-JUN SHU ${ }^{1,2}$, ZHENG-FEI LI ${ }^{2}$, YAO-WEN CHANG ${ }^{2}$, SHENG-YE LIU ${ }^{2}$, \\ WEN-HUI WANG ${ }^{2}$ and XIAOQIANG LI ${ }^{1}$ \\ ${ }^{1}$ Department of Vascular Surgery, The Second Affiliated Hospital of Soochow University, Suzhou, Jiangsu 215000; \\ ${ }^{2}$ Department of Interventional Radiology, The First Hospital of Lanzhou University, Lanzhou, Gansu 730000, P.R. China
}

Received April 10, 2017; Accepted August 22, 2017

DOI: $10.3892 / \mathrm{etm} .2018 .5751$

\begin{abstract}
The effects of different doses of folic acid and vitamin B12 on rabbits with deep vein thrombosis (DVT) and hyperhomocysteinemia were investigated. In total, 60 New Zealand rabbits were divided into untreated control, low-dose and high-dose groups. After inducing DVT, hemorheology and coagulation indexes were measured 3 and 10 days later. We found that both treatment groups performed better than the control group, and the high-dose performed better than the lowdose. Ten days after thrombosis, the levels of Hcy and D-dimer were lower in the high-dose group. Moreover, the changes of lower extremity deep venous thrombosis were significantly reduced in both high- and low-dose groups, but the high-dose group showed the most improvement. The effective rate of the high-dose group was $100 \%$, higher than the rate in the lowdose and control groups. Overall, high-dose of folic acid and vitamin B12 can significantly improve plasma Hcy, coagulation indexes, and pathological changes in the venous thrombosis of the lower extremity.
\end{abstract}

\section{Introduction}

Deep venous thrombosis (DVT) of the lower extremity is a haemal disease involving abnormal circumfluence (1). Once the thrombus occurs, a small fraction of them ablate on their own; however, most thrombus spread gradually to the venous main body of the limbs (2). If timely clinical diagnosis and treatment are not provided, the situation will aggravate with thrombus sequelae, with serious heath consequences. Research suggests the increase of homocysteine (Hcy) levels in plasma is closely related to DVT $(3,4)$. Some studies propose that the metabolic process of hyperplasma Hcy is associated with folic

Correspondence to: Dr Xiaoqiang Li, Department of Vascular Surgery, The Second Affiliated Hospital of Soochow University, 1055 Sanxiang Road, Gusu, Suzhou, Jiangsu 215000, P.R. China E-mail: baqx2065563@163.com

Key words: folic acid, vitamin B12, homocysteine, deep venous thrombosis acid and vitamin B12, and that folic acid and vitamin B12 can lower the plasma levels of Hcy (5-7). Thus, can folic acid and vitamin B12 be used to treat hyperhomocysteinemia with DVT? If so, what are the effects of different doses of folic acid and vitamin B12 on DVT with hyperhomocysteinemia? In this study, we created a rabbit model with DVT and hyperhomocysteinemia and used different doses of folic acid and vitamin B12. We then examined the effect of each treatment to provide experimental support for the treatment of DVT with hyperhomocysteinemia with folic acid and vitamin B12.

\section{Materials and methods}

Experiment animals and treatments. Sixty male New Zealand rabbits of grade SPF were provided by the experimental animal center of Lanzhou University, with body mass of 2.1-3.1 kg. We created the rabbit model of DVT with hyperhomocysteinemia and randomly divided them into three groups: control (treated with normal saline), low-dose (treated with $5 \mathrm{mg} /$ day folic acid $+0.25 \mathrm{mg} /$ day vitamin B12) and high-dose (treated with $15 \mathrm{mg} /$ day folic acid $+0.5 \mathrm{mg} /$ day vitamin B12). Normal saline was obtained from Shanghai Di Ran Dang Cheng Pharmaceutical, folic acid tablets from Fujian Minghua Pharmaceutical, Fujian, China (National Medicine permission number: H19993229), and vitamin B12 from Datong Changxing Pharmaceutical, Shanxi, China (National Medicine permission number: H14022782). The rabbits were kept in a cage with controlled temperature $\left(24^{\circ} \mathrm{C}\right)$ and free access to water. The study was approved by the Ethics Committee of the First Hospital of Lanzhou University.

Hemorheology detection. Three days and 10 days after modeling, $5 \mathrm{ml}$ of whole blood were obtained from the ear artery from each animal and hemorheology indexes such as plasma viscosity, whole blood reduced viscosity at low shear, whole blood reduced viscosity at high shear, and red cell assembling index were detected using a hemorheology detector (Beijing Succeeder Science and Technology Development).

Coagulation function detection. Three days and 10 days after modeling, $3 \mathrm{~m} 1$ whole blood were obtained from the ear artery from each animal, and coagulation function indexes such as fibrinogen, activated partial thromboplastin time, thrombin 
Table I. Hemorheology indexes 3 days after modeling.

\begin{tabular}{lcccc}
\hline Groups & No. & $\begin{array}{c}\text { Plasma viscosity } \\
(\mathrm{mPa} \cdot \mathrm{s})\end{array}$ & $\begin{array}{c}\text { Whole blood } \\
\text { reduced viscosity at } \\
\text { low shear }(\mathrm{mPa} \cdot \mathrm{s})\end{array}$ & $\begin{array}{c}\text { Whole blood reduced } \\
\text { viscosity at } \\
\text { high shear }(\mathrm{mPa} \cdot \mathrm{s})\end{array}$ \\
\hline Control & 20 & $1.72 \pm 0.75$ & $41.35 \pm 1.35$ & $\begin{array}{c}\text { Red cell } \\
\text { assembling } \\
\text { index }\end{array}$ \\
Low-dose & 20 & $1.53 \pm 0.36^{\mathrm{a}}$ & $35.74 \pm 0.85^{\mathrm{a}}$ & $5.83 \pm 0.05$ \\
High-dose & 20 & $1.42 \pm 0.27^{\mathrm{a}, \mathrm{b}}$ & $32.57 \pm 0.62^{\mathrm{a}, \mathrm{b}}$ & $5.66 \pm 0.07^{\mathrm{a}}$ \\
$5.41 \pm 0.04^{\mathrm{a}, \mathrm{b}}$ & $4.44 \pm 0.08^{\mathrm{a}}$ \\
\hline
\end{tabular}

${ }^{\mathrm{a}} \mathrm{P}<0.05$ compared with model control group; ${ }^{\mathrm{b}} \mathrm{P}<0.05$ compared with low-dose group.

Table II. Hemorheology indexes 10 days after modeling.

\begin{tabular}{lcccc}
\hline Groups & No. & $\begin{array}{c}\text { Plasma viscosity } \\
(\mathrm{mPa} \cdot \mathrm{s})\end{array}$ & $\begin{array}{c}\text { Whole blood } \\
\text { reduced viscosity at } \\
\text { low shear }(\mathrm{mPa} \cdot \mathrm{s})\end{array}$ & $\begin{array}{c}\text { Whole blood reduced } \\
\text { viscosity at } \\
\text { high shear }(\mathrm{mPa} \cdot \mathrm{s})\end{array}$ \\
\hline Control & 20 & $1.70 \pm 0.65$ & $40.07 \pm 1.25$ & $\begin{array}{c}\text { Red cell } \\
\text { assembling } \\
\text { index }\end{array}$ \\
Low-dose & 20 & $1.45 \pm 0.31^{\mathrm{a}}$ & $33.32 \pm 0.54^{\mathrm{a}}$ & $5.76 \pm 0.06$ \\
High-dose & 20 & $1.27 \pm 0.23^{\mathrm{a}, \mathrm{b}}$ & $28.55 \pm 0.52^{\mathrm{a}, \mathrm{b}}$ & $5.42 \pm 0.04^{\mathrm{a}}$ \\
$5.01 \pm 0.06^{\mathrm{a}, \mathrm{b}}$ & $4.26 \pm 0.05^{\mathrm{a}}$ \\
\hline
\end{tabular}

${ }^{\text {ap }}<0.05$ compared with model control group; ${ }^{\mathrm{b}}<0.05$ compared with low-dose group.

Table III. Coagulation function 3 days after modeling.

\begin{tabular}{|c|c|c|c|c|c|}
\hline Groups & No. & $\begin{array}{l}\text { Fibrinogen } \\
\qquad(\mathrm{g} / \mathrm{l})\end{array}$ & $\begin{array}{c}\text { Activated partial } \\
\text { thromboplastin time }(\mathrm{sec})\end{array}$ & $\begin{array}{l}\text { Thrombin } \\
\text { time (sec) }\end{array}$ & $\begin{array}{l}\text { Prothrombin } \\
\text { time (sec) }\end{array}$ \\
\hline Control & 20 & $4.23 \pm 0.35$ & $15.12 \pm 0.85$ & $27.75 \pm 0.31$ & $8.76 \pm 0.47$ \\
\hline Low-dose & 20 & $3.64 \pm 0.75^{\mathrm{a}}$ & $17.83 \pm 1.12^{\mathrm{a}}$ & $31.57 \pm 0.52^{\mathrm{a}}$ & $10.03 \pm 0.13^{\mathrm{a}}$ \\
\hline High-dose & 20 & $3.32 \pm 0.54^{\mathrm{a}, \mathrm{b}}$ & $19.05 \pm 0.76^{\mathrm{a}, \mathrm{b}}$ & $33.56 \pm 0.35^{\mathrm{a}, \mathrm{b}}$ & $11.94 \pm 0.13^{\mathrm{a}, \mathrm{b}}$ \\
\hline
\end{tabular}

${ }^{a} \mathrm{P}<0.05$ compared with model control group; ${ }^{\text {b }}<0.05$ compared with low-dose group.

time, and prothrombin time were detected using a coagulation convention detector (Nanjing Perlong Image Documentation Equipment, Nanjing, China).

Biochemical tests. The fully automated biochemical analyzer (Shanghai Hengsheng Medical Apparatus and Instruments Limited Company, Shanghai, China) was used to measure Hcy levels before and 10 days after DVT modeling by enzymatic cycling assay. Latex agglutination test was used to measure plasma D-dimer in days 1 and 10 days after DVT modeling. 10 days after DVT modeling, $5 \%$ thipentone of $0.1 \mathrm{ml} / 100 \mathrm{~g}$ body mass was injected to enterocoelia for anesthesia. Then, rabbits were dissected to expose the saphenous artery, vein, saphenous vein, artery part of left hind limbs, to check thrombus and record if there is bump in the lower limbs. After blood vessel of left hind limb was separated, formalin was applied to fix and conventional pathological section was conducted, with hematoxylin and eosin (H\&E) stain and pathologic histology change of deep venous thrombosis was inspected of rabbit lower extremity under microscopic examination. Color Doppler ultrasound (Jiangsu Jiahua Electronic Equipment Limited Company, Jiangsu, China) was applied to observe prognosis of thrombus.

Statistical analysis. Software SPSS 20.0 (IBM, New York, NY, USA) was used to process data. Enumeration data are shown by rate, $\chi^{2}$ was used to detect and measurement data are presented by mean \pm standard deviation. Comparison between two groups was done by t-test and comparison among several groups applied $\mathrm{F}$ in detection. $\mathrm{P}<0.05$ was considered to indicate a statistically significant difference.

\section{Results}

Hemorheology indexes. We measured hemorheology indexes at days 3 and 10 days after DVT modeling. At day 3, plasma viscosity, whole blood reduced viscosity at low shear, whole blood reduced viscosity at high shear, and red cell assembling 
Table IV. Coagulation function indexes 10 days after modeling.

\begin{tabular}{lccccc}
\hline Groups & No. & $\begin{array}{c}\text { Fibrinogen } \\
(\mathrm{g} / \mathrm{l})\end{array}$ & $\begin{array}{c}\text { Activated partial } \\
\text { thromboplastin time }(\mathrm{s})\end{array}$ & $\begin{array}{c}\text { Thrombin } \\
\text { time (s) }\end{array}$ & $\begin{array}{c}\text { Prothrombin } \\
\text { time (s) }\end{array}$ \\
\hline Control & 20 & $4.16 \pm 0.41$ & $15.05 \pm 0.62$ & $28.11 \pm 0.54$ & $9.01 \pm 0.47$ \\
Low-dose & 20 & $3.64 \pm 0.75^{\mathrm{a}}$ & $17.83 \pm 1.12^{\mathrm{a}}$ & $35.45 \pm 0.43^{\mathrm{a}}$ & $12.16 \pm 0.22^{\mathrm{a}}$ \\
High-dose & 20 & $3.32 \pm 0.54^{\mathrm{a}, \mathrm{b}}$ & $19.05 \pm 0.76^{\mathrm{a}, \mathrm{b}}$ & $38.33 \pm 0.46^{\mathrm{a}, \mathrm{b}}$ & $14.43 \pm 0.55^{\mathrm{a}, \mathrm{b}}$ \\
\hline
\end{tabular}

${ }^{\mathrm{a}} \mathrm{P}<0.05$ compared with model control group; ${ }^{\mathrm{b}} \mathrm{P}<0.05$ compared with low-dose group.

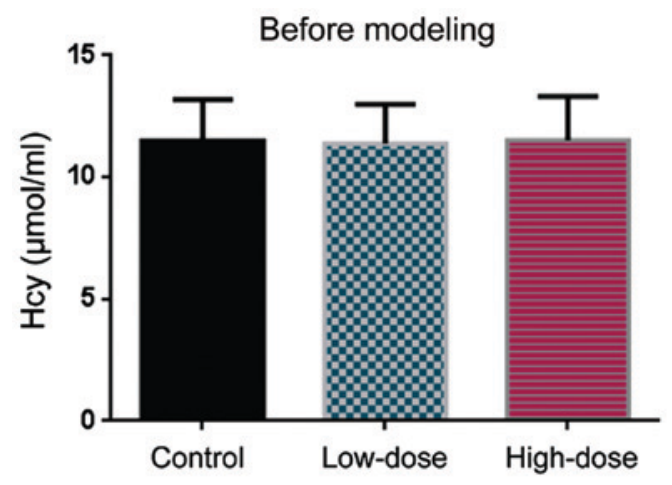

Figure 1. Hcy level before DVT modeling.

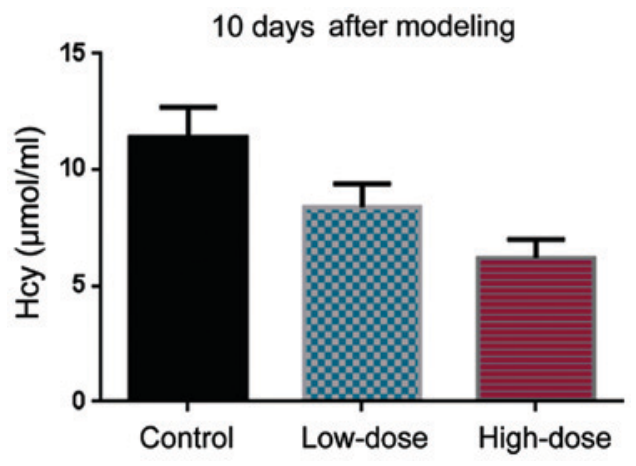

Figure 2. Hcy level 10 days after DVT modeling.

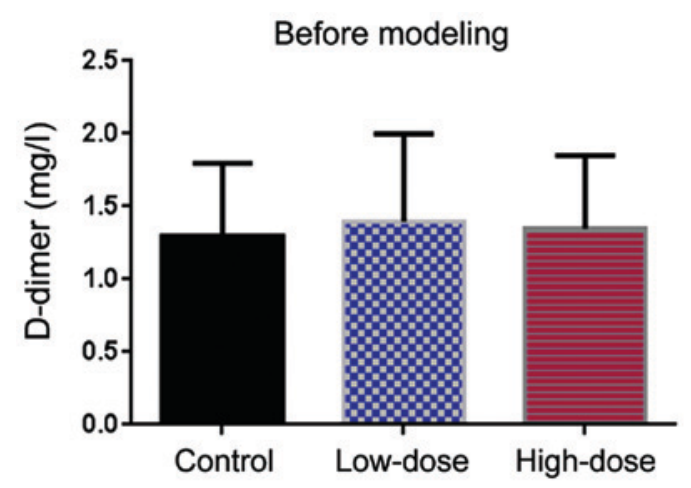

Figure 3. D-dimer level before DVT modeling.

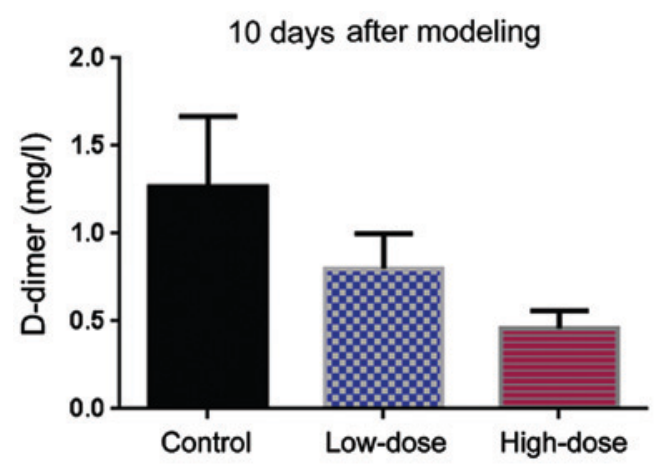

Figure 4. D-dimer level 10 days after DVT modeling. index were significantly lower in the low-dose and high-dose groups compared to controls (Table I). At day 10, all the values improved in the three groups, but the low- and highdose groups still showed lower values than the control group (Table II). Additionally, the hemorheology indexes for the high-dose group were superior to those of low-dose group at days 3 and 10, suggesting the benefits of the higher dose (Tables I and II).

Coagulation function. We next measured coagulation indexes in the rabbits 3 and 10 days after DVT modeling. The levels of fibrinogen at days 3 and 10 were significantly lower in the two treatment groups compared with controls (Tables III and IV). The coagulation indexes APTT, PT, and TT were significantly higher in both treatment groups compared controls (Tables III and IV). The coagulation function indexes of the high-dose group were superior to those of the low-dose group (Tables III and IV).

Hcy level. Before DVT modeling, the Hcy levels were comparable in the control, low-dose, and high-dose groups (Fig. 1). 10 days after DVT modeling, Hcy levels in the low-dose group were lower than in the control group (Fig. 2). The Hcy levels in the high-dose group were even lower than those in the lowdose group (Fig. 2).

D-dimer. Before DVT modeling, the level of D-dimer level was comparable in the three groups (Fig. 3). Ten days after modeling, the level of D-dimer in the low-dose group was lower than in the control group (Fig. 4). The Hcy levels in the high-dose group were even lower than those in the low-dose group (Fig. 4). 
Table V. Thrombus recovery.

\begin{tabular}{|c|c|c|c|c|c|}
\hline Groups & No. & Excellent & Effective & Non-effective & $\begin{array}{c}\text { Effective rate of } \\
\text { treatment }(\%)\end{array}$ \\
\hline Control & 20 & 0 & 0 & 20 & 0 \\
\hline Low-dose & 20 & 13 & 2 & 5 & $75^{\mathrm{a}}$ \\
\hline High-dose & 20 & 12 & 8 & 0 & $100^{\mathrm{a}, \mathrm{b}}$ \\
\hline
\end{tabular}

${ }^{\mathrm{a}} \mathrm{P}<0.05$ compared with model control group; ${ }^{\mathrm{b}} \mathrm{P}<0.05$ compared with low-dose group.
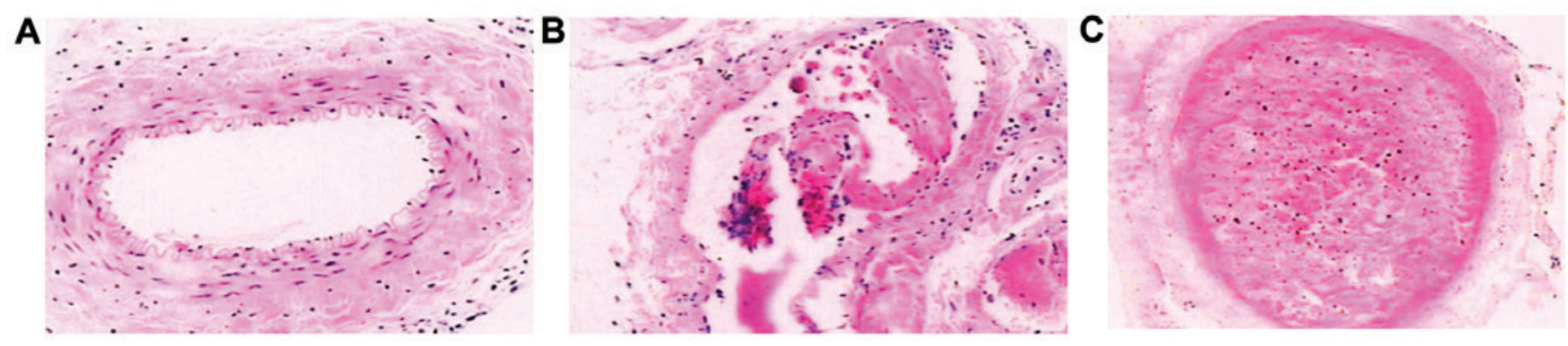

Figure 5. Vein cross section 10 days after DVT modeling (H\&E x100). (A) High-dose group; (B) low-dose group; (C) control group.
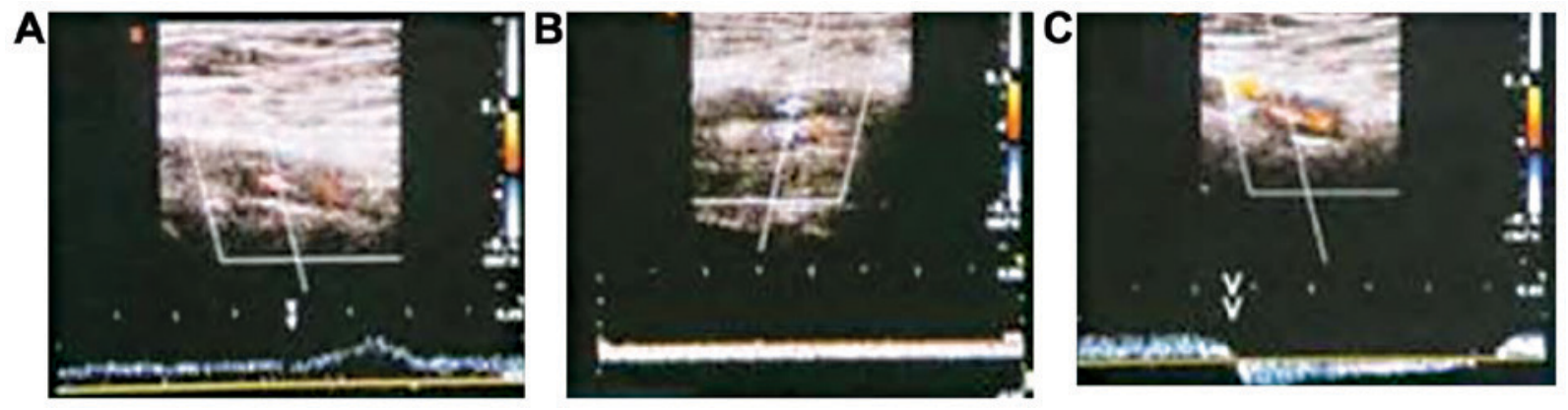

Figure 6. Venous thrombus ultrasonogram 10 days after DVT modeling. (A) Control group; (B) low-dose group; (C) high-dose group.

Vein pathology. Ten days after DVT modeling, we compared the change of lower extremity deep venous thrombosis of highdose group and low-dose group were significantly reduced, while the improvement level of high-dose group was the best. Each layer of the normal femoral vein under light microscope recovered well in the high-dose group, without edema in loose connective tissue of adventitia (Fig. 5A). Partial serious intima damage was visible in the low-dose group, with endothelial falling partially (Fig. 5B). In the control group, endothelial cells of vein blood vessel fell off, with obvious adventitia edema, a great amount of fibrous protein aggregation in 'latticed' fibrin, full of red cells and a little deciduous endothelial cells, forming thrombus filling the whole lumen (Fig. 5C).

Thrombus recovery. Ten days after DVT modeling, the effective rate of treating lower extremity deep venous thrombosis with the high doses of folic acid and vitamin B12 was 100\%, whereas the effective rate of the low-dose treatment was $75 \%$ (Table V). The control group showed no benefits and had an effective rate of $0 \%$ (Table V). Ten days after DVT modeling, the femoral venous wall echo was enhanced in the control group, with uneven intima echo incrassation and a little blood flow signal in the femoral vein (Fig. 6A). The femoral venous wall of the low-dose group thickened, with full solid and medium echo, blood flow signal in lumen around, dark color suggesting that flow rate was low (Fig. 6B). The femoral venous wall of the high-dose group thickened with strong echo in lumen, colorful blood flow presenting irregular fullness (Fig. 6C).

\section{Discussion}

Thrombus is caused by blood solidification and abnormal viscosity due to obstacles affecting its fluidity; this results in the formation of thrombocytes and activation of blood coagulation factor (8-10). DVT is one of the results where abnormal hemorheology and viscosity induce ischemia and anoxia of organs (11-13). Therefore, correcting blood viscosity and improving blood coagulation function indexes have an extremely important role in the prevention and treatment of DVT.

Our study showed that for 3 days and 10 days after DVT modeling, hemorheology and coagulation indexes were the best 
in the high-dose folic acid and vitamin B12 group. Some reports have proposed that Hcy is a thrombus-forming agent, and high Hcy could induce deep venous thrombosis (14-17). In addition, plasma D-dimer has been proposed to have a forewarning function for thrombus and hypercoagulable state $(18,19)$. Ten days after DVT modeling, we found that the levels of Hcy and D-dimer improved the most in the high-dose group.

Through histopathologic examination, we found that 10 days after DVT modeling the high-dose and low-dose groups showed significant improvement in the change of lower extremity deep venous thrombosis. Deep venous thrombosis of lower extremity with color Doppler ultrasound diagnosis has some advantages, such as simple operation, safety and high efficiency, low cost, repeatability and direct observation, and the detection of related lesions and bleeding features around blood vessels (20). Our results also showed that after DVT modeling, the effective rate of lower extremity deep venous thrombosis treatment of high-dose group was $100 \%$. The results of color Doppler ultrasound diagnosis of DVT corresponded to our findings in histopathologic examination. This validated the feasibility and high efficiency of color Doppler ultrasound diagnosis for deep venous thrombosis of the lower extremity.

In summary, folic acid and vitamin B12 have clear therapeutic effects in a rabbit model of DVT with hyperhomocysteinemia. The high-doses we tried improved various relevant symptoms, including the levels of Hcy and D-dimer, hemorheology, coagulation function, and vein pathology. Overall, these studies support the use of high doses of folic acid and vitamin B12 to treat DVT.

\section{References}

1. Mouravas H, Verettas D, Kazakos K, Xarhas K, Panagiotou N and Ellinas P: Homocysteine and its relationship to deep venous thrombosis in patients undergoing total knee or hip arthroplasty. Hippokratia 14: 185-188, 2010.

2. Hosseini S, Kalantar E, Hosseini MS, Tabibian S, Shamsizadeh M and Dorgalaleh A: Genetic risk factors in patients with deep venous thrombosis, a retrospective case control study on Iranian population. Thromb J 13: 35, 2015.

3. Hosseini S, Kalantar E, Hosseini MS, Tabibian S, Shamsizadeh M and Dorgalaleh A: Genetic risk factors in patients with deep venous thrombosis, a retrospective case control study on Iranian population. Thromb J 13: 35, 2015.

4. Martinelli I, Cattaneo M, Panzeri D, Taioli E and Mannucci PM: Risk factors for deep venous thrombosis of the upper extremities. Ann Intern Med 126: 707-711, 1997.

5. Roy S, Sable P, Khaire A, Randhir K, Kale A and Joshi S: Effect of maternal micronutrients (folic acid and vitamin B12) and omega 3 fatty acids on indices of brain oxidative stress in the offspring. Brain Dev 36: 219-227, 2014.

6. Shu XJ, Li ZF, Chang YW, Liu SY and Wang WH: Effects of folic acid combined with vitamin B12 on DVT in patients with homocysteine cerebral infarction. Eur Rev Med Pharmacol Sci 21: 2538-2544, 2017.
7. Ravari H, Zafarghandi MR, Alvandfar D and Saadat S: Serum homocysteine in deep venous thrombosis, peripheral atherosclerosis and healthy Iranians: A case-control study. Pak J Biol Sci 12: 1019-1024, 2009.

8. Lungren MP, Ward TJ, Patel MN, Racadio JM and Kukreja K: Endovascular thrombolysis to salvage central venous access in children with catheter-associated upper extremity deep vein thrombosis: Technique and initial results. J Thromb Thrombolysis 40: 274-279, 2015.

9. Prandoni P, Tormene D, Dalla Valle F, Concolato A and Pesavento R: D-dimer as an adjunct to compression ultrasonography in patients with suspected recurrent deep vein thrombosis. J Thromb Haemost 5: 1076-1077, 2007.

10. Rodrigues CA, Morelli VM, DA Silveira RC, D'Almeida V and Lourenço DM: Homocysteine reduction by B-vitamin supplementation increases t-PA and PAI-1 levels in patients with venous thromboembolism. J Thromb Haemost 5: 195-198, 2007.

11. Duplessis M, Girard CL, Santschi DE and Pellerin D: An economic model evaluating the supplementation of folic acid and vitamin $\mathrm{B}_{12}$ given around parturition and in early lactation on dairy farms in Québec, Canada. Can J Anim Sci 94: 737-747, 2014.

12. Malý R, Masopust J, Hosák L and Konupcíková K: Assessment of risk of venous thromboembolism and its possible prevention in psychiatric patients. Psychiatry Clin Neurosci 62: 3-8, 2008.

13. Negrão L and Nunes P; Portuguese Group for the Study of Peripheral Neuropathy: Uridine monophosphate, folic acid and vitamin B12 in patients with symptomatic peripheral entrapment neuropathies. Pain Manag 6: 25-29, 2016.

14. Cebeci F, Onsun N, Ulusal HA and Inan B: The relationship between deep vein thrombosis and erythema nodosum in male patients with Behçet's disease. Eur Rev Med Pharmacol Sci 18: 3145-3148, 2014.

15. Negrão L, Almeida P, Alcino S, Duro H, Libório T, Melo Silva U, Figueira R, Gonçalves S and Neto Parra L: Effect of the combination of uridine nucleotides, folic acid and vitamin B12 on the clinical expression of peripheral neuropathies. Pain Manag 4: 191-196, 2014.

16. Criado PR, Alavi A and Kirsner RS: Elevated levels of coagulation factor VIII in patients with venous leg ulcers. Int J Low Extrem Wounds 13: 130-134, 2014.

17. Falcone $M$ and Serra P: Massive pulmonary embolism in a woman with leiomyomatous uterus causing pelvic deep venous thrombosis. Ann Ital Med Int 20: 104-107, 2005.

18. Shammas NW, Shammas G, Bryan D, Rauba J, Dippel E and Jerin M: Predictors of target lesion revascularization in patients undergoing lower extremity percutaneous interventions. J Invasive Cardiol 21: 266-269, 2009.

19. Sagban TA, Scharf RE, Wagenhäuser MU, Oberhuber A, Schelzig H, Grabitz K and Duran M: Elevated risk of thrombophilia in agenesis of the vena cava as a factor for deep vein thrombosis. Orphanet J Rare Dis 10: 3, 2015.

20. Al-Hameed F, Al-Dorzi HM, Shamy A, Qadi A, Bakhsh E, Aboelnazar E, Abdelaal M, Al Khuwaitir T, Al-Moamary MS, Al-Hajjaj MS, et al: The Saudi clinical practice guideline for the diagnosis of the first deep venous thrombosis of the lower extremity. Ann Thorac Med 10: 3-15, 2015. International (CC BY-NC-ND 4.0) License. 